\title{
Diurnal evolution of cloud base heights in convective cloud fields from MSG/SEVIRI data
}

\author{
R. Meerkötter and L. Bugliaro \\ Deutsches Zentrum für Luft- und Raumfahrt, Institut für Physik der Atmosphäre, Oberpfaffenhofen, 82234 Wessling, \\ Germany
}

Received: 30 July 2008 - Published in Atmos. Chem. Phys. Discuss.: 3 November 2008

Revised: 2 February 2009 - Accepted: 23 February 2009 - Published: 10 March 2009

\begin{abstract}
This study shows that it is possible to retrieve the temporal evolution of cloud base heights in convective broken cloud fields from data of the SEVIRI instrument onboard the geostationary satellite Meteosat-9. Presented and discussed are time dependent base heights with a temporal resolution of $15 \mathrm{~min}$ from morning to afternoon. Cloud base heights retrieved from SEVIRI data are also compared with independent measurements of a ceilometer, with condensation levels calculated from radiosonde data and with base heights obtained from an application of the method to NOAA/AVHRR data. The validation has been performed for three days in the year 2007 and for seven test areas distributed over Germany and neighbouring countries. The standard deviations of the absolute differences between cloud base heights from Meteosat- 9 and radiosonde measurements as well as between NOAA/AVHRR and Meteosat-9 results are both of the order of $\pm 290 \mathrm{~m}$. The correlation coefficient is 0.53 for the comparison of satellite with radiosonde measurements and 0.78 for the intercomparison of the satellite measurements. Furthermore, it is shown that the method retrieves the temporal evolution of cloud base heights in very good agreement with time dependent ceilometer measurements.
\end{abstract}

\section{Introduction}

Cloud properties play an essential role in the climate system because they significantly affect the energy budget in the Earth-atmosphere system. Besides the microphysical cloud composition, especially the macroscopical structures such as cloud coverage, cloud base height, and vertical geometrical

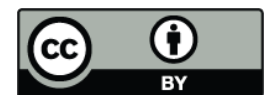

Correspondence to: R. Meerkötter (ralf.meerkoetter@dlr.de) extension influence the shortwave and longwave radiation budget at the surface as well as at the top of the atmosphere. Furthermore, clouds are highly variable in time and space and changing cloud field structures feed back on the time dependent atmospheric energy budgets and related atmospheric processes.

In this paper we focus on water clouds, especially on convective clouds. These clouds usually show a pronounced evolution during the day. Over land cloud base heights of convective clouds can for example be lifted several hundred meters from morning to afternoon. Individual clouds often grow to form large cells with cloud top heights reaching the tropopause region.

For retrieving cloud top heights from satellite data various algorithms have been developed that meanwhile provide operational products (see e.g. Weisz et al., 2007, and referenced papers). More complex is the retrieval of cloud base heights from space. Some authors present methods for deriving cloud base heights or cloud geometrical thicknesses, mainly for stratiform clouds, from polar orbiting satellites (e.g., Minnis et al., 1995; Wilheit and Hutchison, 2000; Chakrapani et al., 2002; Hutchison, 2002; Kassianov et al., 2003; Bennartz, 2007). With polar orbiting satellites, e.g., MetOp, NOAA, TERRA, or AQUA, cloud fields can be observed with a rather high spatial resolution, but only be probed at a few distinct times during the day. Forsythe et al. (2000) used geostationary GOES-8 data and showed that a satellite-based cloud classification scheme combined with surface reports of the cloud base height yields an improvement over cloud base heights estimates from surface reports alone.

Our ambition was to directly retrieve time dependent base heights of convective clouds by the use of data from the SEVIRI instrument onboard the European geostationary satellite Meteosat-9, in the following abbreviated as MSG (Meteosat Second Generation). MSG/SEVIRI provides data with

Published by Copernicus Publications on behalf of the European Geosciences Union. 


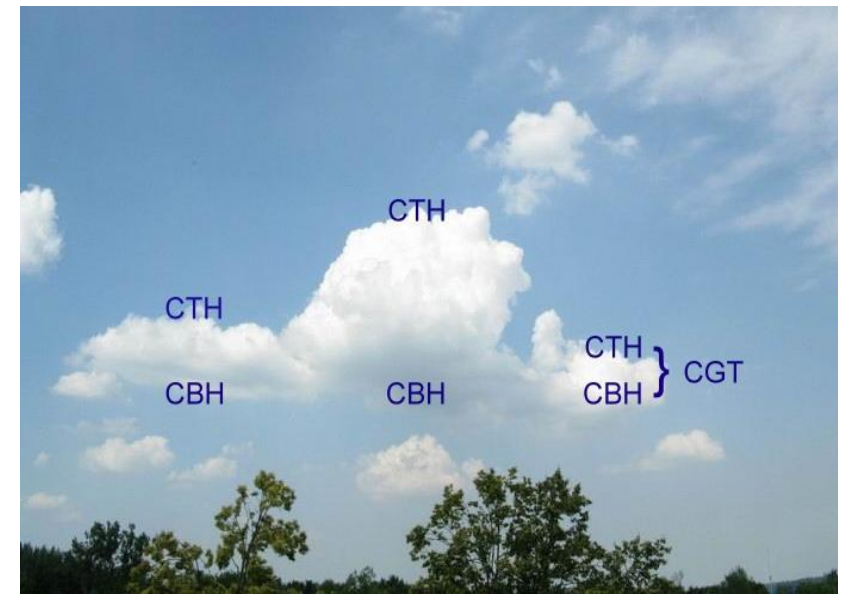

Fig. 1. Example for convective clouds in different stages of their individual life cycle. All clouds start growing from a constant condensation level. For retrieving the cloud base height $(\mathrm{CBH})$ only clouds with small optical thicknesses were selected. CTH and CGT denote the cloud top height and the cloud geometrical thickness, respectively.

a temporal resolution of $15 \mathrm{~min}$. The knowledge about area wide and temporally resolved cloud base heights would have manifold implications for atmospheric science. For example, the combined information about cloud base and cloud top heights is essential for the reconstruction of real cloud field structures. The analysis of cloud effects on the surface radiation budget and herewith climate research topics would benefit from such data sets. Also three-dimensional simulations in the UV, solar and terrestrial spectral range for the purpose of understanding radiative transfer processes or for interpreting measurements need realistic microphysical and macroscopical cloud parameters as input. Furthermore, applications in the field of solar energy questions are imaginable. For example, cloud top and base heights determine the projection of cloud shadows on the surface and are therefore especially important for the calculation of the direct solar flux.

This paper ties in with the method of retrieving cloud base heights from NOAA/AVHRR data that has already been introduced by Meerkötter and Zinner (2007). In the following we show new results, i.e. time dependent cloud base heights retrieved from MSG/SEVIRI data and compare them with temporally continuous measurements of a ceilometer, with condensation levels obtained from radiosonde data, and with cloud base heights retrieved from NOAA/AVHRR data. Focusing on the region of Central Europe makes this study especially challenging because MSG/SEVIRI scans Europe under rather large viewing angles of about $50-70^{\circ}$.

At first, Sect. 2 briefly summarises the basic assumptions and the principle of the retrieval method. Section 3 then describes the satellite data and the main retrieval steps. Section 4 is devoted to the validation concept and Sect. 5 presents and discusses the results. Finally concluding remarks are formulated in Sect. 6.

\section{Approach and basic assumptions}

The principle ideas underlying our approach are: convective clouds start growing at a rather constant condensation level; convective clouds appear as geometrically, i.e. vertically, thin clouds in their earliest stage of growth; and the cumulus condensation level is nearly constant over large areas at any time (Fig. 1). These assumptions are valid for air masses widely unaffected by advective motions and forming homogeneous fields of vertical temperature and humidity profiles. For geometrically thin water clouds the assumption of an adiabatic vertical liquid water content (LWC) is often satisfied and errors introduced by uncertainties in estimating cloud optical thickness (COT) and microphysical parameters from satellite data remain small (shown below).

The cloud base height $(\mathrm{CBH})$ can be expressed as the difference of the cloud top height (CTH) and the cloud geometrical thickness (CGT):

$\mathrm{CBH}=\mathrm{CTH}-\mathrm{CGT}$

The CTH can be retrieved from satellite measured radiances in spectral window channels in the infrared (see below). Meerkötter and Zinner (2007) showed that CGT can be derived from COT and the effective radius $r_{\text {eff }}$ according to

$\mathrm{CGT}=\left(10 / 9 \mathrm{COT} \rho r_{\mathrm{eff}} / C_{w}\right)^{1 / 2}$

where COT and $r_{\text {eff }}$ are also retrieved from satellite data. Equation (2) is derived under the assumption of an adiabatic model which describes the vertical profile of cloud microphysics assuming that a saturated cloud air parcel is lifted adiabatically from the cloud base height without exchange of heat with the surrounding air. It is an approximation of real conditions but it is justified in the early stages of convective cloud growth before either collisional growth of droplets or strong mixing due to strong turbulence occur.

In Eq. (2) $\rho$ denotes the density of water $\left(1 \mathrm{~g} / \mathrm{cm}^{3}\right) . C_{w}$ is a condensation coefficient that linearly relates the adiabatic LWC to the CGT. It is expressed as a function of temperature and pressure near the cloud base (e.g. Brenguier et al., 2000; Zinner et al., 2006). Since the approach of estimating $\mathrm{CBH}$ is based on geometrically relatively thin water clouds $(\mathrm{CGT} \approx 250 \mathrm{~m}, \mathrm{COT} \approx 10)$, temperature and pressure retrieved for the cloud top are used for $C_{w}$. Here the pressure is obtained from cloud top temperature $\left(T_{\text {top }}\right)$ and heights provided by radiosonde profiles. In principal also model data like those provided for example by the ECMWF can be used.

Again, the key idea of the method is to select only those convective clouds for retrieval that are in their earliest stage of growth, herewith optically and geometrically relatively thin. Retrieving geometrical thicknesses for such clouds is less error prone than for geometrically thick clouds. However, by taking advantage of the fact that the condensation level is nearly constant the method also allows to assign retrieved CBHs to those clouds in a cloud field that are existing 
in a later individual development stage, i.e. with larger vertical extensions at the same time.

\section{Satellite measurements}

The method presented in this paper is applied to data of the Spinning Enhanced Visible and InfraRed Imager (SEVIRI) radiometer aboard the Meteosat Second Generation (MSG) satellite. Meteosat-9/SEVIRI combines a fast repeat cycle of 15 min with comprehensive spectral information over the whole Earth disk. It comprises 11 spectral channels in the visible and infrared spectral range with a spatial resolution of $3 \times 3 \mathrm{~km}^{2}$ at the sub-satellite point $\left(0^{\circ} \mathrm{E}\right)$. Furthermore, it is equipped with an additional broadband high resolution visible (HRV) channel with a ground sampling distance of about $1 \mathrm{~km}$ at the sub-satellite point. This resolution is comparable to that of the polar orbiting AVHRR radiometers which are flown on NOAA and MetOp satellites. AVHRR is a 5 channel instrument with a spatial resolution of $1.1 \mathrm{~km}$ at nadir and its data will be used here for the evaluation of cloud base heights derived from MSG/SEVIRI.

\subsection{Cloud parameters from MSG/SEVIRI data}

Cloud detection is based on simple threshold tests applied to the visible channels centred at 0.6 and $0.8 \mu \mathrm{m}$ on one side, and on the more elaborated cirrus tests presented in Krebs et al. (2007). For cloudy pixels thermodynamic phase, CTH, COT and $r_{\text {eff }}$ are determined together with sub-pixel cloud fraction.

Cloud phase is determined by means of Krebs et al. (2007), i.e. if a cirrus cloud is detected the ice phase is assigned, otherwise the water phase.

Cloud top heights have been derived from equivalent blackbody temperatures measured in the IR channel at $10.8 \mu \mathrm{m}$. Although this channel is located within a spectral window region, an atmospheric correction has nevertheless to be performed to account for weak water vapour absorption along the slant path through the atmosphere from the cloud top height to the top of atmosphere. The cloud fields investigated in this study are located over Central Europe which is seen by MSG/SEVIRI under a viewing angle of around $57^{\circ}$. The atmospheric correction has been determined by the use of a radiative transfer model. Standard atmospheres as midlatitude summer and subarctic summer (Anderson et al., 1986) have been used as input because they well fit the temperature and water vapour profiles on the days selected for this study (Sect. 4.1). Radiative transfer calculations have been performed for a spectral interval that corresponds to the SEVIRI $10.8 \mu \mathrm{m}$ channel. Top heights of the water clouds are assumed to be located $3000 \mathrm{~m}$ above the ground. Comparing the atmospheric temperature at the top of the model cloud with the blackbody temperature resulting from the radiative transfer calculation gives a difference of
$3 \mathrm{~K}$. Related sensitivity studies reveal that an uncertainty in the atmospheric temperature of $\pm 3 \mathrm{~K}$ above the cloud results in an uncertainty of about $0.16 \mathrm{~K}$ for the temperature correction. A cloud top height of $2000 \mathrm{~m}$ instead of $3000 \mathrm{~m}$ implies a corresponding uncertainty of $0.33 \mathrm{~K}$. To give a benchmark, temperature changes of $\pm 0.3 \mathrm{~K}$ correspond to base height changes of $\pm 50 \mathrm{~m}$ in case of a temperature gradient with $0.6 \mathrm{~K} / 100 \mathrm{~m}$. Thus, we add $3 \mathrm{~K}$ to the MSG measurements to obtain the physical temperature $T_{\text {top }}$ of cloud tops. Finally, this temperature is matched against the temperature profile gained from radiosonde ascents at 12:00 UTC to derive the CTH (see Sect. 4.2).

The determination of COT and $r_{\text {eff }}$ is based on the method described by Nakajima and King (1990). It has been adapted to the MSG/SEVIRI channel at $0.6 \mu \mathrm{m}$ and the near-IR channel centred at $1.6 \mu \mathrm{m}$. Whereas the reflectivity in the channel at $0.6 \mu \mathrm{m}$ is mainly determined by COT, it is also sensitive to the effective radius in the channel at $1.6 \mu \mathrm{m}$. Simultaneous comparison of observed reflectivities in these two spectral bands with corresponding pre-calculated quantities yields the optical thickness and the effective radius that best reproduces the measurements. Required look-up tables are produced with the radiative transfer code libRadtran (Mayer and Kylling, 2005) as a function of solar and satellite zenith angle, relative azimuth angle, surface albedo, COT, and $r_{\text {eff. }}$. The underlying atmospheric profiles are taken from the standard atmosphere midlatitude summer (Anderson et al., 1986). An application to real atmospheres as described in Sect. 4.2 would imply small uncertainties in the retrieval

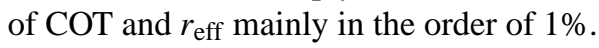

Finally, by applying two threshold tests to the broad-band HRV channel of MSG/SEVIRI a high resolution cloud mask can be determined and thus sub-pixel cloud cover.

\subsection{Cloud parameters from NOAA/AVHRR data}

Data from the Advanced Very High Resolution Radiometer (AVHRR) aboard the polar orbiting NOAA and MetOp is acquired at the Deutsches Fernerkundungsdatenzentrum (DFD) of Deutsches Zentrum für Luft- und Raumfahrt (DLR) in Oberpfaffenhofen and processed with the APOLLO software (Kriebel et al., 2003). The products used in this study are cloud type, cloud top temperatures and cloud optical thickness according to Meerkötter and Zinner (2007).

\section{3 $\mathrm{CBH}$ retrieval based on NOAA/AVHRR and MSG/SEVIRI data}

The method originally developed for NOAA/AVHRR data (Meerkötter and Zinner, 2007) and applied for this study to retrieve $\mathrm{CBHs}$ can be summarised as:

1. Areas of size $100 \times 100 \mathrm{~km}^{2}$ around radiosonde stations are selected. 
2. In selected scenes of broken water clouds all totally cloudy pixels with $5 \leq \mathrm{COT} \leq 7$ are extracted in areas defined in step 1.

3. For these pixels $T_{\text {top }}$ is estimated from the thermal AVHRR channels.

4. Each $T_{\text {top }}$ is assigned to a CTH by the aid of a radiosonde profile.

5. CGT values are inferred according to Eq. (2) with COT values from step 1 by assuming a fixed $r_{\text {eff }}$ of $10 \mu \mathrm{m}$ (processing scheme does not provide $r_{\text {eff }}$ ).

6. For each totally cloudy pixel a $\mathrm{CBH}$ is estimated according to Eq. (1).

7. $\mathrm{CBH}$ values are spatially averaged over the selected areas.

For retrieving CBHs from MSG/SEVIRI this procedure has been adapted, extended and improved:

1. Areas of size $100 \times 100 \mathrm{~km}^{2}$ around radiosonde stations are selected.

2. In selected scenes of broken water clouds all totally cloudy pixels with $8 \leq \mathrm{COT} \leq 12$ are extracted. Sub-pixel coverage is provided by the high resolution cloud mask. Cirrus covered pixels are excluded.

3. For these pixels $T_{\text {top }}$ is estimated from the SEVIRI channel at $10.8 \mu \mathrm{m}$.

4. Each $T_{\text {top }}$ is assigned to a CTH by the aid of a radiosonde profile.

5. CGT values are inferred according to Eq. (2) with COT values from step 1 and by using $r_{\text {eff }}$ retrieved from MSG/SEVIRI data.

6. For each totally cloudy pixel the $\mathrm{CBH}$ is estimated according to Eq. (1).

7. $\mathrm{CBH}$ values are spatially averaged over the selected areas.

On one hand, with SEVIRI we make direct use of the information about cloud phase, effective droplet radius and sub-pixel cloud fraction. On the other hand, the reduced SEVIRI spatial resolution (with respect to AVHRR) of about $4 \times 5 \mathrm{~km}^{2}$ over Central Europe requires a re-definition of the COT intervals for the selection of thin water clouds. From empirical studies we found that a COT range from 8 to 12 is adequate. Further increasing the upper COT limit would additionally select clouds with larger geometrical thicknesses which in turn implies an application of the method to clouds for which the adiabatic assumption (Sect. 2) would no longer be valid. As a consequence calculated CGT values become increasingly too small and the $\mathrm{CBH}$ is lifted. Shifting the

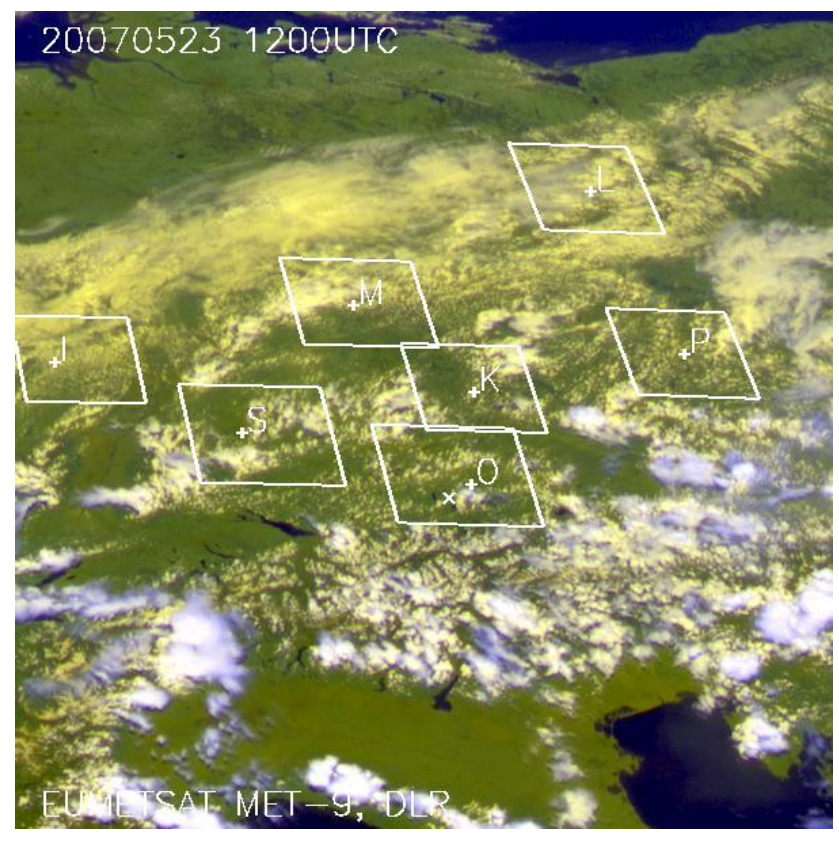

Fig. 2. Test areas for cloud base height retrievals. Marked are the locations of the radiosonde stations Idar-Oberstein, Stuttgart, Oberschleißheim, Kümmersbruck, Meiningen, Prag, and Lindenberg denoted by I, S, O, K, M, P, and L, respectively. The $\mathrm{x}$ in area $\mathrm{O}$ marks the ceilometer station at DLR Oberpfaffenhofen. The figure shows broken cloud fields on 23 May 2007 as observed by the broadband HRV channel of MSG/SEVIRI at 12:00 UTC. For the movie showing the temporal behaviour of the convective cloud fields from 08:00 to 17:30 UTC on 23 May see supplemental material: http://www.atmos-chem-phys.net/9/1767/ 2009/acp-9-1767-2009-supplement.zip.

interval center to smaller COT values, e.g. to 5-7 as for the NOAA/AVHRR method, still works in a number of cases but simultaneously it increases the probability of semitransparent cloud fractions occuring in the sub-pixel scale. As a result retrieved cloud top temperatures increase and CTHs as well as CBHs decrease. A reduction of the interval width, for example to a range from 9 to 10 , would reduce the population of analysable cloud pixels in a scene. Thus, a COT range from 8 to 12, together with the sub-pixel cloud fraction extracted from the HRV channel ensures that we are considering individual shallow clouds or geometrical thin fragments of extended clouds that are filling the MSG/SEVIRI pixels by minimising negative effects on the $\mathrm{CBH}$ retrieval.

\section{Application and validation}

\subsection{Selected days with convective clouds}

Three days in the year 2007 were selected for testing the method, 23 May 2007, 30 May 2007, and 30 July 2007. These were days with broken cloud fields forming over Ger- 


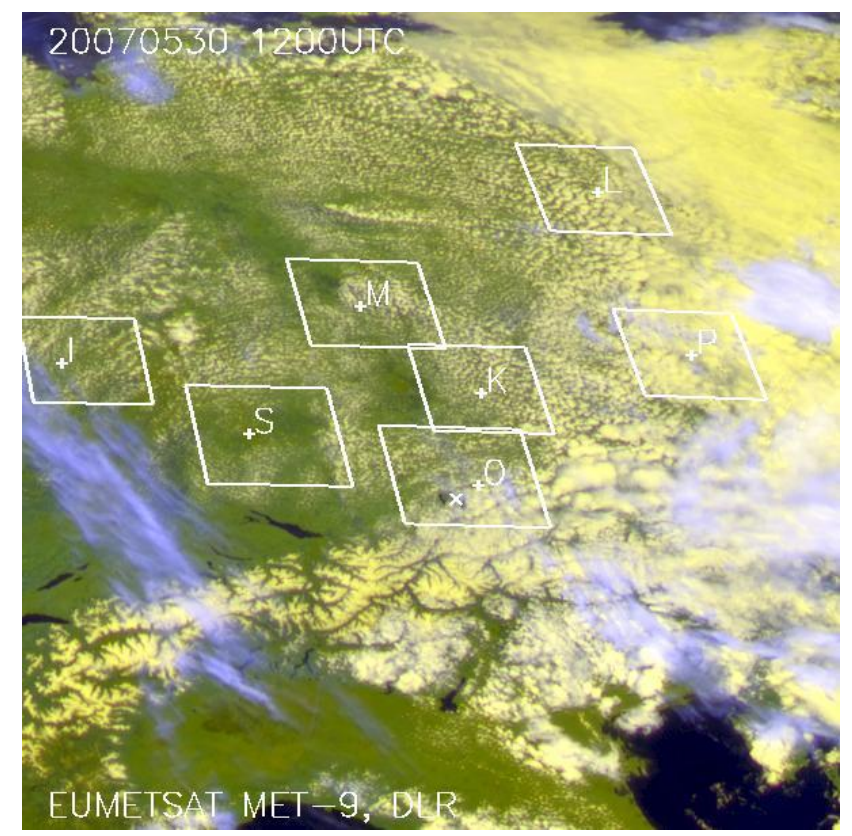

Fig. 3. As in Fig. 2, but for 30 May 2007.

many and neighbouring countries. Figures $2-4$ are false colour composites including the HRV channel of SEVIRI and show the cloud structures as observed at 12:00 UTC. The spatial and temporal variation of the convective cloud fields from 08:00 to 17:30 UTC on all three days can be seen in the supplemental material (see http://www.atmos-chem-phys. net/9/1767/2009/acp-9-1767-2009-supplement.zip). On 23 May 2007 cumulus clouds start their evolution process at about 08:30 UTC over Southern Germany, reaching a maximum cloud cover during noon time. In the later afternoon they tend to build local cloud clusters and cumulonimbus clouds accompanied by a reduction of cloud cover over wide areas around them. The 30 May 2007 scene is dominated by small scale cumuli over the entire day. In the morning hours several cirrus fields appear over Southern Germany, at noon time and henceforward cirrus bands of larger scale are approaching from the West. On 30 July 2007 broken clouds embedded in a north-westerly flow are distributed over Germany with individual cloud sizes being clearly smaller over Southern Germany. From Mid to Northern Germany the clouds tend to spread during the day.

\subsection{Test areas and radiosonde data}

To obtain data for validation we select test areas that are located around radiosonde stations. These test areas are distributed over Mid and Southern Germany as well as over the Czech Republic (Figs. 2-4). The 12:00 UTC radiosonde ascents from the stations Idar-Oberstein (No. 10618), Stuttgart (No. 10739), Oberschleißheim near München (No. 10868), Kümmersbruck (No. 10771), Meiningen (No. 10548), Lindenberg (No. 10393), and Prag (No. 11520) are used. In the

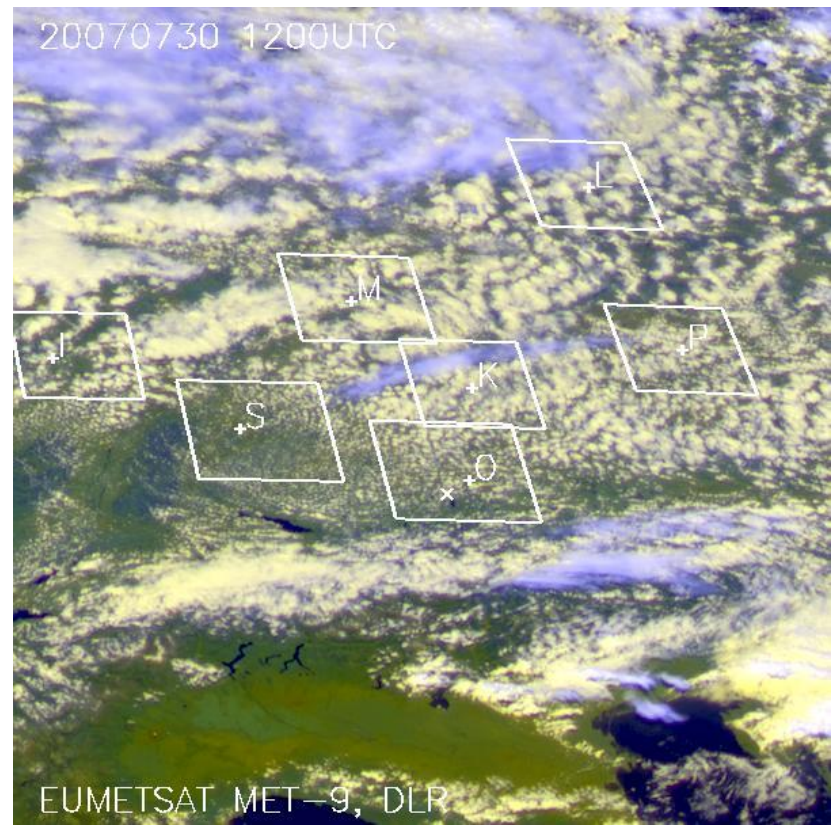

Fig. 4. As in Fig. 2, but for 30 July 2007.

following these locations are denoted by $\mathrm{I}, \mathrm{S}, \mathrm{O}, \mathrm{K}, \mathrm{M}, \mathrm{L}$, and $\mathrm{P}$, respectively. In particular, vertical profiles of pressure, temperature and moisture are employed.

Radiosonde ascents provide the lifted condensation level (LCL) that can easily be calculated from temperature and dew point information in atmospheric layers near the surface according to the well known formula

$\mathrm{LCL}=125\left(T-T_{d}\right)$

Equation (3) gives the LCL in meter, $T$ and $T_{d}$ are near surface values of temparature and dew point, respectively. By applying Eq. (3) we calculate average dew point differences from all available radiosonde data points below $100 \mathrm{~m}$ above ground. At noon-time and under conditions of a well mixed boundary layer it is justified to assume that the LCL represents the cumulus condensation level. As stated by Lawrence (2005) Eq. (3) is generally accurate to within about $2 \%$ for relative humidities between $50 \%$ and $100 \%$ and for temperatures between $0^{\circ} \mathrm{C}$ and $30^{\circ} \mathrm{C}$.

In order to present a further independent information from radiosonde measurements we also analyse relative humidity profiles and assume the $\mathrm{CBH}$ where the relative humidity first reaches at least $99 \%$. Under conditions of broken clouds this may not provide data everywhere, but where appropriate data are available we add them to our results presented and discussed in Sect. 5.

\subsection{Ceilometer data}

In contrast to radiosondes, ceilometer measurements provide a high temporal evolution of the CBH. One test area contains the ceilometer station at the Deutsches Zentrum für Luft- und 



Fig. 5. Area averaged cloud base heights $(\mathrm{CBH})$, area averaged cloud top heights $\left(\mathrm{CTH}_{\mathrm{av}}\right)$, and maximum cloud top heights $\left(\mathrm{CTH} \mathrm{H}_{\mathrm{max}}\right)$ as a function of daytime from MSG/SEVIRI data for test areas on 23 May 2007. Also shown is the lifted condensation level (LCL) and where available the height where the relative humidity reaches 99\% ( $\mathrm{RH}_{99 \%}$ ), both quantities are obtained from radiosonde data at 12:00 UTC. Additionally marked is the CBH from NOAA/AVHRR data at 12:24 UTC. Horizontal dashed lines denote the altitude of the radiosonde stations above mean sea level. DLR ceilometer measurements are available for Area O.

Raumfahrt (DLR) close to Oberpfaffenhofen and close to the radiosonde station Oberschleißheim near Munich in a distance of about $30 \mathrm{~km}$ to DLR (Fig. 2, Area O). Since 1998 a modified Vaisala ceilometer has been operating $24 \mathrm{~h}$ a day at DLR, producing vertical backscatter profiles every $30 \mathrm{~s}$. The system comprises a laser operating at $900 \mathrm{~nm}$ wavelength with a peak pulse power of $30 \mathrm{~W}$. Its vertical resolution is determined by the specific pulse width $(20 \mathrm{~ns})$ and the sampling rate $(20 \mathrm{MHz})$. For hard targets this translates into a vertical resolution of $7.5 \mathrm{~m}$. For the detection of softer targets as boundary layer water clouds signal to noise thresholds and a defined number of consecutive samples (here 3 ) above a threshold are applied. This leads to a vertical resolution of $22.5 \mathrm{~m}$ at best.

\subsection{Intercomparison of satellite data}

As mentioned, $\mathrm{CBH}$ values have already been retrieved from an application of our method to noon overpass data of the AVHRR instrument aboard the polar orbiting NOAA satellites. Comparing the results from the MSG/SEVIRI with those from NOAA/AVHRR data should give a hint about the applicability of the method to different satellite instruments. This is especially instructive since viewing geometry and spatial resolution of both instruments are significantly different over Europe. 


\section{Results and discussion}

Figures 5-7 show the diurnal evolution of the $\mathrm{CBH}$ and the maximum cloud top heights $\left(\mathrm{CTH}_{\max }\right)$ derived from MSG/SEVIRI data. Results are presented for those areas where data availability and cloud conditions provide the most complete temporal sequences for $\mathrm{CBH}$ and $\mathrm{CTH}_{\max }$. Also shown is the CBH obtained from an application of the method to NOAA/AVHRR overpass data at noon-time as well as the CBH (LCL) resulting from radiosonde data at 12:00 UTC. As mentioned, all satellite retrieved CBHs represent spatial averages over each test area at the time of measurement. Bars at the symbols represent the $\mathrm{CBH}$ standard deviation resulting from $\mathrm{CBH}$ variations in the ensemble of optically thin clouds which have been pre-selected for the retrieval. Ceilometer measurements as a function of time are available for Area O containing the DLR ceilometer station.

As a first impression, many of the curves in Figs. 5-7 show a $\mathrm{CBH}$ that is increasing with time from the morning hours into the afternoon. Meteosat and also ceilometer data (e.g., Figs. 5e, 7a, c, d) exhibit this feature which results from an increase of the difference between air temperature and dew point temperature at ground level which in turn is caused by solar heating during the day.

It is further possible to derive the $\mathrm{CTH}_{\max }$ for each MSG time slot. With both, $\mathrm{CBH}$ and $\mathrm{CTH}_{\max }$, as a function of time we obtain an indication about the temporal evolution of the maximum cloud geometrical thicknesses. As can be seen in Figs. 5-7 maximum geometrical thicknesses vary from day to day and during daytime. For example, on 23 May 2007 geometrical thicknesses remain in the order of about $600 \mathrm{~m}$ during the whole day for Area I (Fig. 5a), whereas for Area M on the same day the geometrical cloud thickness shows a more pronounced variation as a function of time with a maximum in the order of about $2500 \mathrm{~m}$ at noon time (Fig. 5e).

It should be noted that cloud geometrical thicknesses from MSG/SEVIRI are also affected by the spatial resolution of $4 \times 5 \mathrm{~km}^{2}$ over Europe. As a consequence, sub-pixel cloud top structures will be smoothed out and in comparison to real cloud top peaks the resulting $\mathrm{CTH}_{\max }$ will have the tendency of being reduced. This is confirmed by the finding that already the AVHRR instrument having a resolution of about $1 \times 1 \mathrm{~km}^{2}$ at sub-satellite point reveals higher $\mathrm{CTH}_{\max }$. For example, on 23 May 2007 a $\mathrm{CTH}_{\max }$ of $2462 \mathrm{~m}$ and a maximum geometrical thickness of $1546 \mathrm{~m}$ is retrieved from AVHRR data for Area I at 12:24 UTC. At the same time the $\mathrm{CTH}_{\text {max }}$ is $5385 \mathrm{~m}$ for Area $\mathrm{M}$ with a maximum vertical cloud extension of $3917 \mathrm{~m}$. Maximum top heights from MSG/SEVIRI at 12:30 UTC are $1759 \mathrm{~m}$ for Area I and $3943 \mathrm{~m}$ for Area M. Although retrieved CTHs differ due to different instrument resolution, retrieved CBHs from MSG/SEVIRI and NOAA/AVHRR agree very well. The reason is that for both instruments the calculation of the cloud geometrical thickness after Eq. (2) is preceded by a selection of optically and geometrically thin clouds that are usually
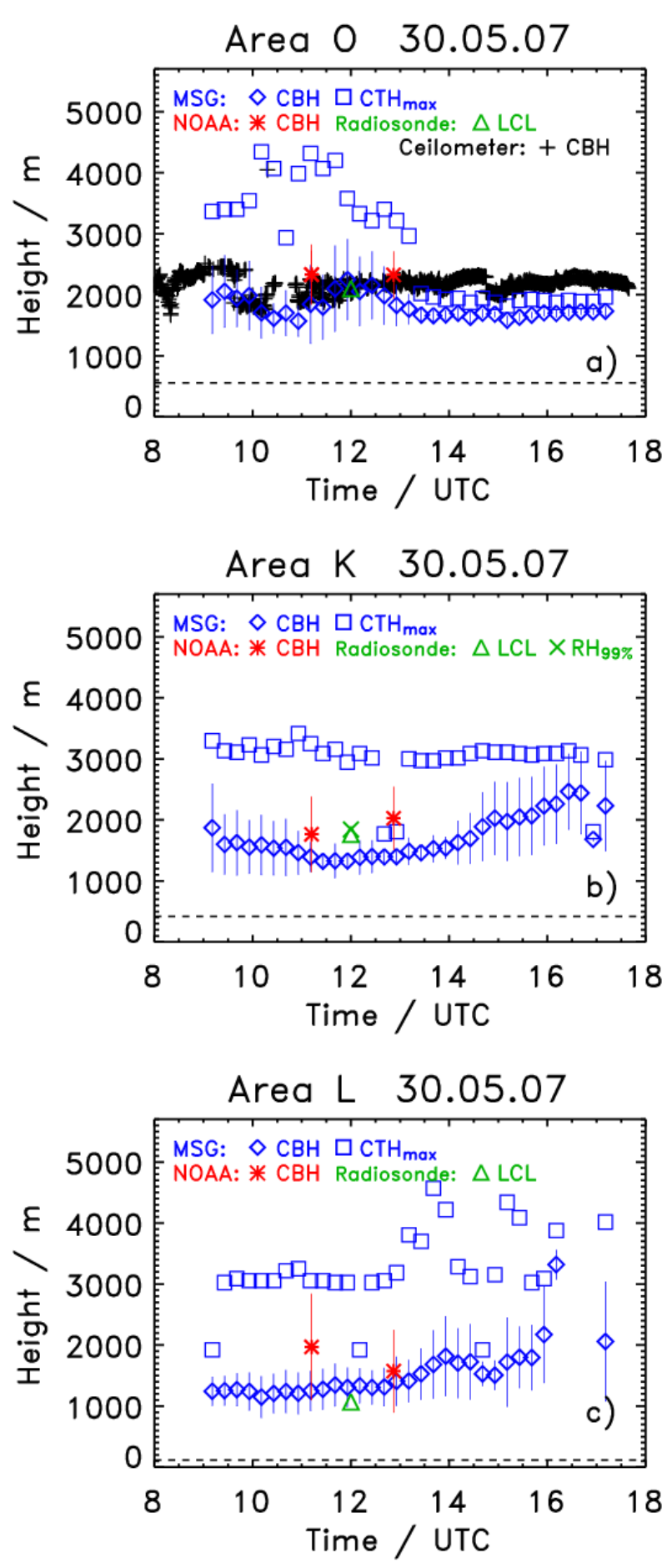

Fig. 6. As in Fig. 5, but for 30 May 2007 and without $\mathrm{CTH}_{\mathrm{av}}$.

forming at the condensation level in their early life stage. For such clouds it can also be expected that differences between cloud top temperature and cloud-environment temperature remain small since the atmospheric temperature profile and the curve for the moist adiabatic lapse rate starting at condensation level are still close to each other. 

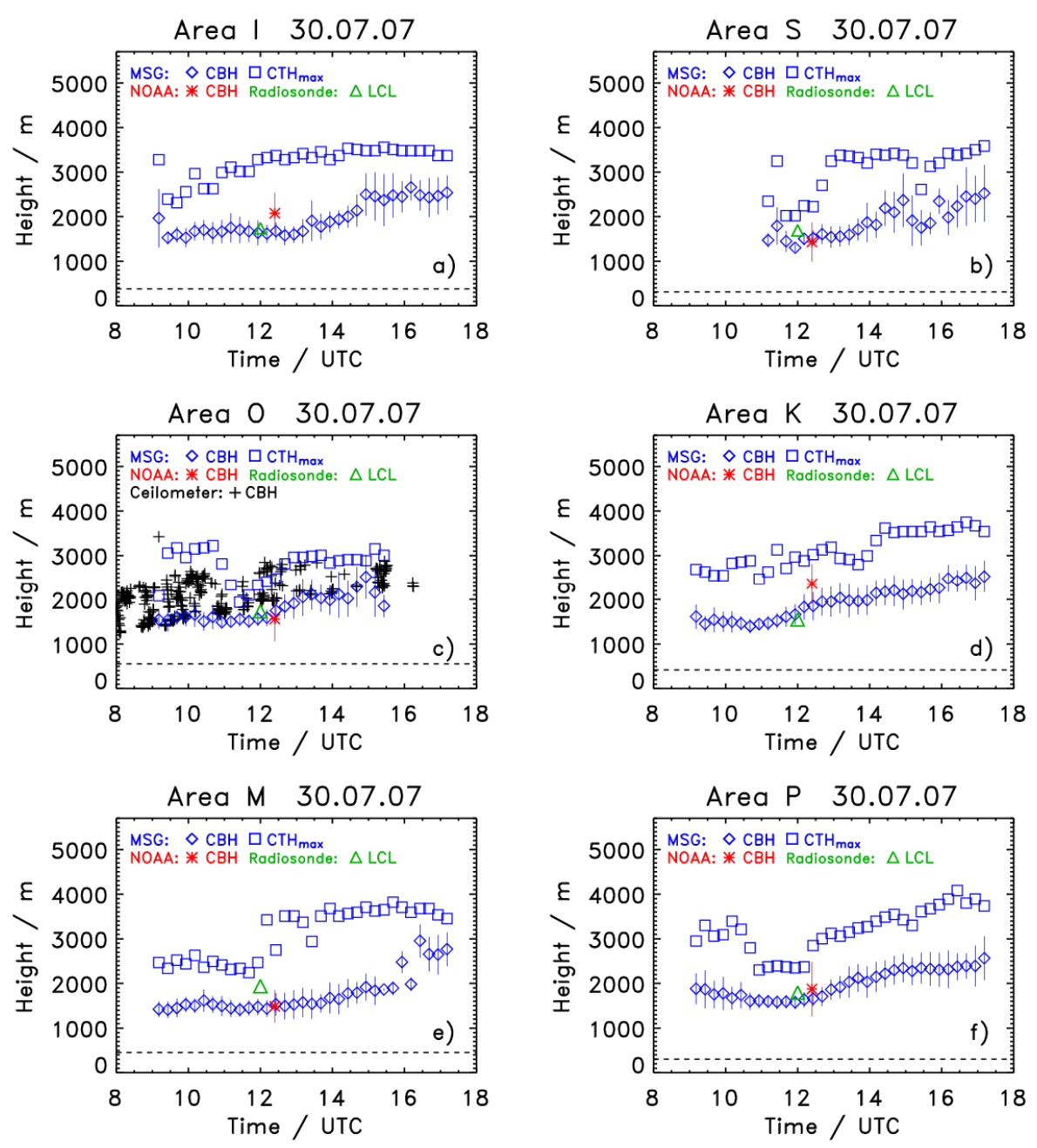

Fig. 7. As in Fig. 5, but for 30 July 2007 and without $\mathrm{CTH}_{\mathrm{av}}$.

The $\mathrm{CBH}$ as a function of time does not necessarily follow the curve of $\mathrm{CTH}_{\max }$ as can for example be seen in Figs. 5e, $\mathrm{f}$, or $7 \mathrm{~b}$. Such a behaviour is not surprising and in accordance to meteorological processes. Cloud top heights are mainly controlled by inversion layers, whereas the cloud base heights depend on the temperature and humidity conditions near the surface. Nevertheless, also $\mathrm{CTH}_{\max }$ varies throughout the day. Some cases show relative minima at distinct times (e.g., Fig. 7c, f). These features are probably due to situations where temporarily no cloud within a test area reaches its potential maximum top height near an existing inversion layer.

Typical examples for the temporal behaviour of spatially averaged cloud top heights $\left(\mathrm{CTH}_{\mathrm{av}}\right)$ are shown in Fig. 5. In analogy to $\mathrm{CTH}_{\max }$ and $\mathrm{CBH}$ the differences between $\mathrm{CTH}_{\mathrm{av}}$ and $\mathrm{CBH}$ represent the temporal evolution of average cloud geometrical thicknesses. The curves for $\mathrm{CTH}_{\mathrm{av}}$ and $\mathrm{CBH}$ show that average thicknesses can vary strongly during daytime from $100 \mathrm{~m}$ to $1 \mathrm{~km}$ (Fig. 5e, f) or remain relatively constant over the day (Fig. 5a, b). Although $\mathrm{CTH}_{\mathrm{av}}$ values are mainly found at levels in the lower half of the maximum cloud thickness, the temporal evolution of average geometrical thicknesses follow qualitatively the diurnal course of maximum geometrical thicknesses.

A direct comparison between MSG/SEVIRI retrieved CBHs with $\mathrm{CBHs}$ from NOAA/AVHRR and between MSG/SEVIRI retrieved CBHs and the LCL from radiosonde data is shown in Fig. 8a and b, respectively. The figures present results from all six test areas at noon-time on 23 May 2007 and 30 July 2007, and from Areas O, K, and L on 30 May 2007. MSG/SEVIRI results for the Areas I, S, and P are incomplete on 30 May 2007 because these Areas are temporarily cloud-free or temporarily covered by cirrus or stratus clouds (see also supplemental material: http://www.atmos-chem-phys.net/9/1767/ 2009/acp-9-1767-2009-supplement.zip). Additionally given are statistical parameters in Fig. 8a and b: mean of absolute differences, "NOAA minus MSG" and "radiosonde 
minus MSG"; the standard deviation of absolute differences; and the correlation coefficient. CBH differences result in $+139.5 \mathrm{~m}$ for "NOAA minus MSG" and in $+8.7 \mathrm{~m}$ for "radiosonde minus MSG". The number of data points is small and both mean absolute differences are within the respective standard deviations. The scatter obtained for the satellite retrieved CBHs is certainly caused by different spatial resolutions, different viewing geometries, and slight differences in the methods for deriving cloud optical thicknesses from MSG and NOAA.

In case of comparing area averaged $\mathrm{CBHs}$ from MSG/SEVIRI with radiosondes data it should be taken into account that the radiosonde represents temperature and humidity measurements at a distinct point in the atmosphere which cannot entirely describe the atmospheric inhomogeneities within areas of about $100 \times 100 \mathrm{~km}^{2}$. Furthermore, entrainment into the air parcels during ascent may change their water vapour mixing ratios in a way that the average condensation level deviates from an LCL that is calculated from data of a local radiosonde measurement. Looking into the profiles of the relative humidity reveals that the radiosondes enter a cloud during ascent not in all our cases of broken cloud fields. Nevertheless we add to Figs. 5a, c, e, and $6 \mathrm{~b}$ those heights at which the relative humidity first reaches 99\% and regard this as a further information about the cloud base height. Except for Area O on 23 May 2007 (Fig. 5c) where the height assigned to $\mathrm{RH}=99 \%$ is about $350 \mathrm{~m}$ higher than the LCL all other cases give an agreement in the order of $100 \mathrm{~m}$. In Area O on 23 May 2007 the radiosonde probably enters the cloud horizontally from the side at a higher level. The better agreements in Figs. 5a, e, and $6 \mathrm{~b}$ should be interpreted in view of the fact that the radionsonde measurements have a height resolution of about $150 \mathrm{~m}$ at condensation level.

Figures $5 \mathrm{c}, 6 \mathrm{a}$, and $7 \mathrm{c}$ display the diurnal cycle of retrieved CBHs from MSG/SEVIRI in comparison to time dependent measurents of the DLR ceilometer. Figure 9ac compares MSG/SEVIRI results with smoothed curves of the ceilometer measurements, i.e. with hourly averages and minimum values, in this way better illustrating how the CBHs retrieved from MSG/SEVIRI follow the minimum values of the ceilometer measurements. On 23 May 2007 the ceilometer signals show an intermittent distribution over the day (Fig. 5c) which is caused by the relatively low cloud cover and by an inhomogeneous distribution of clouds in Area $\mathrm{O}$ (Fig. 2 and supplemental material: http://www.atmos-chem-phys.net/9/1767/2009/ acp-9-1767-2009-supplement.zip). Thus, the CBH retrieval in some cases is based on a reduced number of pixels that were related to thin clouds which consequently enhances the variabilty of retrieved CBHs. This is the reason why MSG/SEVIRI derived CBHs show a scatter that is more pronounced than for example in Area S (Fig. 5b). The radiosonde LCL as well as the NOAA/AVHRR retrieved CBHs are close to the MSG/SEVIRI and ceilometer results at noontime on this day.
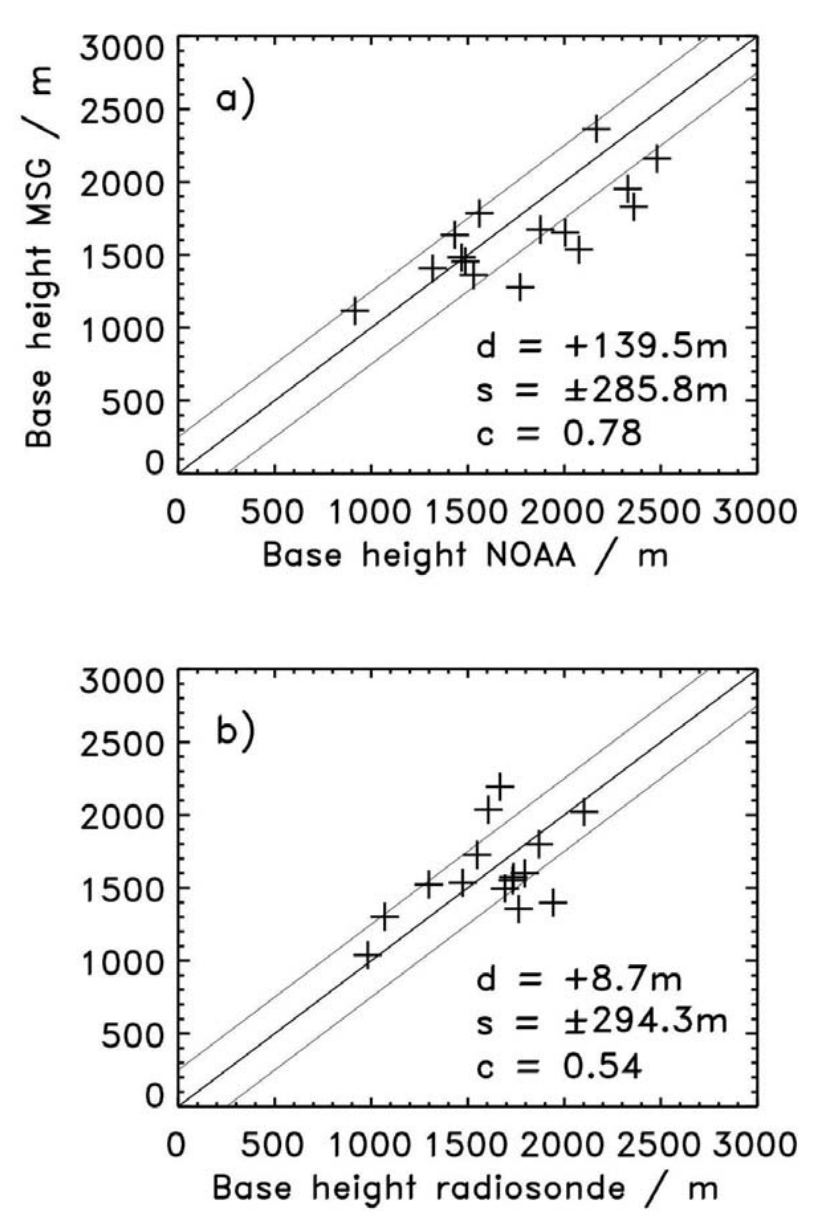

Fig. 8. Cloud base heights from MSG/SEVIRI data against cloud base heights from NOAA/AVHRR data (a) and against lifted condensation levels from radiosonde data (b). Additionally given are mean absolute differences for "MSG minus NOAA" and for "MSG minus radiosonde" denoted by $d, s$ is the standard deviation of the absolute differences and $c$ the correlation coefficient.

On 30 May 2007 clouds in Area O appear as small scale cumulus clouds with homogenous coverage, temporarily spreading into small stratocumulus fields in the afternoon (see supplemental material: http://www.atmos-chem-phys. net/9/1767/2009/acp-9-1767-2009-supplement.zip). Correspondingly the ceilometer provides a rather continuous signal with only a few temporal gaps (Fig. 9b). Apart from the morning hours the ceilometer indicates cloud bases at a nearly constant altitude. CBHs retrieved from two NOAA overpasses at 11:12 UTC and 12:52 UTC show a good agreement to the ceilometer measurements. The LCL derived from radiosonde data lies almost exactly on the ceilometer signals at 12:00 UTC. MSG retrieved CBHs follow the ceilometer signal quite well until about 13:00 UTC. After 13:00 UTC the CBHs as well as the $\mathrm{CTH}_{\max }$ values from MSG/SEVIRI are systematically below the ceilometer 
signals even though showing a likewise constant temporal distribution. Analysing MSG/SEVIRI cloud products in the afternoon reveals a decreasing cloud top height and a reduction of the cloud coverage which means that individual clouds become smaller and more flat in Area $\mathrm{O}$ and that the real temperature profile could have been changed. It should be considered that also the ceilometer provides a point measurement and that local cloud structures above the ceilometer can have CBHs deviating from those retrieved for MSG/SEVIRI pixels that are located away from the ceilometer due to sparser clouds. Note, further north in Area $\mathrm{K}$ the characteristic of the temporal evolution of $\mathrm{CBH}$ and $\mathrm{CTH}_{\max }$ is clearly different (Fig. 6b).

Striking on 30 July 2007 is that the ceilometer signals are more or less evenly distributed between $\mathrm{CBH}$ and $\mathrm{CTH}_{\max }$ (Fig. 7c) with the minimum values from MSG/SEVIRI clearly following the minima of the ceilometer measurements. Furthermore, ceilometer data show a temporal increase which is very similar to the MSG/SEVIRI data (Fig. 9c). Ceilometer signals at higher altitudes are probably due to CBHs of clouds spreading below an inversion in a later stage of their individual life cycle. The radiosonde ascent of Oberschleißheim actually reports an inversion layer between $2550 \mathrm{~m}$ and $2720 \mathrm{~m}$ at 12:00 UTC and the higher ceilometer signals do obviously not exceed that limiting altitude. Apparently MSG/SEVIRI gives no CBH at the higher level. This is probably again an effect of spatial resolution, SEVIRI does not resolve small cloud fragments that can be detected by the ceilometer. The radiosonde LCL as well as CBHs from AVHRR are again in very good agreement to the CBH from SEVIRI at noon-time on 30 July 2007.

The differences between satellite retrieved $\mathrm{CBHs}$ and ceilometer or radiosonde measurements as well as between the CBHs retrieved from different satellite instruments imply several sources of uncertainties. Especially should be taken into account:

1. The retrieval is based on the condition that MSG/SEVIRI pixels are completely cloud covered. Therefore effects are expected that are related to the inherent spatial inhomogeneity of the selected cloud fields and the 3-dimensional nature of radiative transfer (especially in the solar spectral range). The derivation of cloud properties from MSG/SEVIRI data is based on the assumption that pixels are homogeneous and independent of each other. Deviations from these assumptions can cause biases and uncertainties. Zinner and Mayer (2006) showed that cloud inhomogeneity introduces some bias and considerable noise into the optical thickness and effective radius retrieved at the resolution of MSG/SEVIRI. For instance, cloud optical thickness can be over- or underestimated by $20 \%$ even for fully cloud covered pixels. On the other hand and this is an advantage for our method - the impact of such uncertainties weakens for the optically and
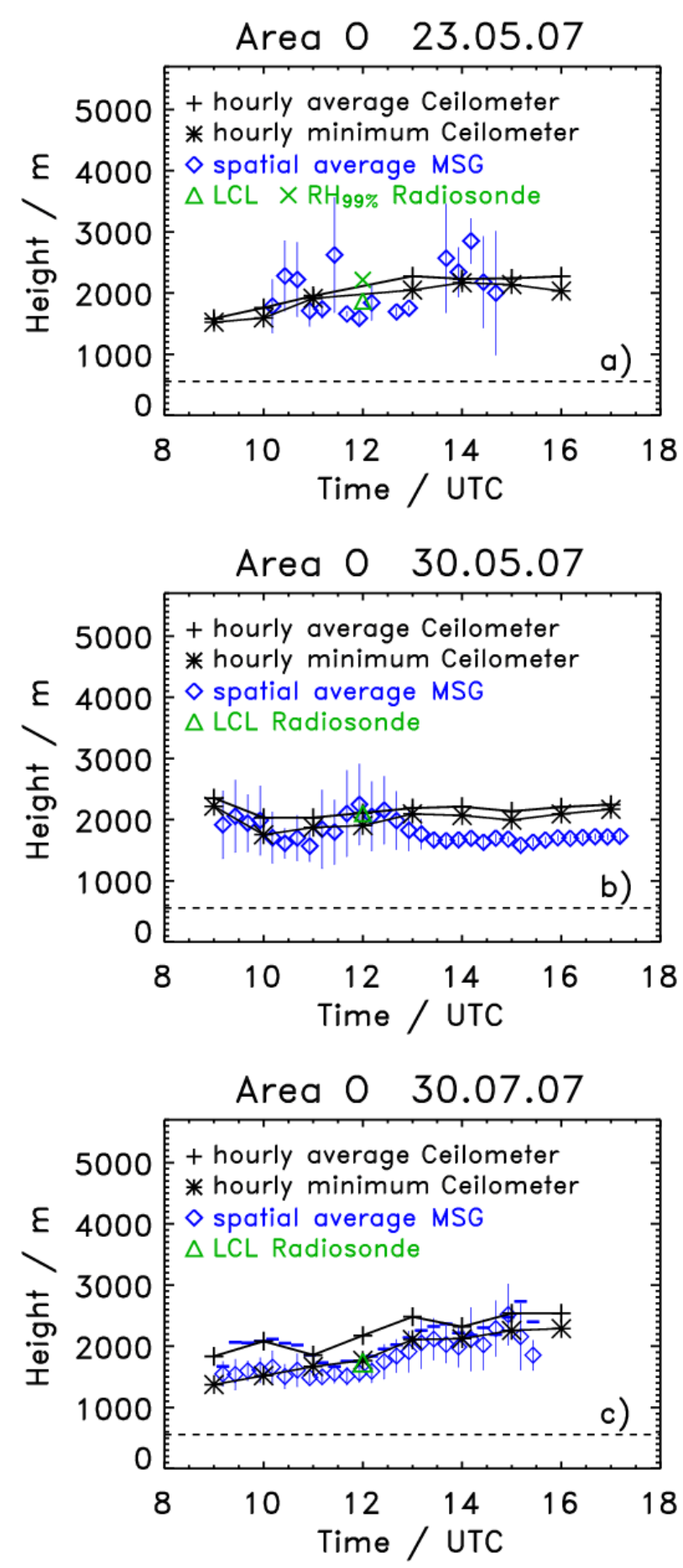

Fig. 9. Cloud base heights from MSG data and from radiosonde data LCL and $\mathrm{RH}_{99 \%}$ in comparison to hourly minimum and hourly averaged values of the ceilometer signals for Area O on (a) 23 May, (b) 30 May, and (c) 30 July 2007.

geometrically thin water clouds as were selected with our retrieval method, see also Fig. 1 in Meerkötter and Zinner (2007). 
2. The calibration accuracy of the solar SEVIRI channels is 5\% (EUMETSAT, 2004), while uncertainties in calibration of the SEVIRI $10.8 \mu \mathrm{m}$ channel are below $0.25 \mathrm{~K}$ at $300 \mathrm{~K}$ (Schmetz et al., 2002). An error in the order of $0.25-0.5 \mathrm{~K}$ could be expected due to the atmospheric correction employed ( $3 \mathrm{~K}$ ) that can slightly vary as a function of cloud top height and atmospheric water vapour profile. As far as the estimation of the cloud top temperature is concerned an uncertainty due to calibration and atmospheric correction in the order of $0.5 \mathrm{~K}$ should therefore be realistic. This corresponds to about $80-100 \mathrm{~m}$ in the CTH and CBH estimate, respectively.

3. The accuracy of the DLR ceilometer corresponds to its vertical resolution which amounts to $22.5 \mathrm{~m}$ at best (see Sect. 4.3).

4. Finally it should be mentioned that we use the radiosonde measurements at 12:00 UTC for the assignment of cloud heights and regard this as valid over the whole day. Although this approach may be justified for a certain time interval in case of a well mixed boundary layer, it should be taken into account that temporally changing temperature profiles could have a significant impact on the $\mathrm{CBH}$ retrieval.

Although it is rather difficult to exactly quantify the accuracy of the method for retrieving cloud base heights, the following numerical example illustrates the advantage of selecting optically and geometrically thin water clouds for our CBH retrieval: Water clouds with COT $=10$ and $r_{\text {eff }}=10 \mu \mathrm{m}$ have geometrical thicknesses in the order of $250 \mathrm{~m}$ after Eq. (2). Assuming that the uncertainties mentioned above result in an uncertainty of the cloud geometrical thickness of $30 \%$ this amounts to $3.8 \%(5 \%)$ uncertainty in the $\mathrm{CBH}$ retrieval if the cloud base is located at an altitude of $2000 \mathrm{~m}$ $(1500 \mathrm{~m})$. Errors in the retrieval of the cloud top height have of course to be added.

\section{Concluding remarks}

This study shows the diurnal evolution of cloud base heights $(\mathrm{CBH})$ in convective broken cloud fields retrieved with a method based on data from the SEVIRI instrument aboard the geostationary satellite Meteosat-9 (MSG). The presented results also reveal time dependent features of the $\mathrm{CBH}$ that are typical for convective cloud fields. The accuracy of the method has been demonstrated by comparing CBHs with independent measurements of a ceilometer, with condensation levels calculated from radiosonde data, and with CBHs obtained from an application of the method to NOAA/AVHRR data.

The main advantage of using data from geostationary satellites lies in their high temporal resolution. This is especially valuable since the $\mathrm{CBH}$ is a cloud parameter with significant impact on the radiation budget at the surface. Together with the cloud top height which can simultaneously be retrieved from MSG/SEVIRI data, it is possible to reconstruct realistic cloud field structures as a function of time. Together with the information of area wide 3-d temperature fields, e.g., from radiosondes or from data of numerical weather prediction models, the method will finally allow a reconstruction of the temporal evolution of broken cloud fields over regions of a large scale.

In this paper convective cloud fields observed during day are treated. Certainly the method will supplement CBH retrieval methods developed for other cloud types as for example mentioned in the introduction of this paper. One of the next steps will be to apply and validate the method in other regions than Central Europe, as for example over the Atlantic, in Mediterranean areas, or in the tropics. With respect to an application of the method to larger data sets an automated processing tool that identifies regions actually covered by convective clouds would be a useful extension.

The potential of MSG/SEVIRI for retrieving the CBH for convective clouds is already evident from this study. As mentioned in the introduction it ranges from atmospheric radiative transfer modeling and radiation budget studies to applications in climate research when analysing long-term data sets.

Acknowledgements. We are grateful to J. Streicher (DLR) for making available the ceilometer data and G. Gesell (DLR) for processing NOAA/AVHRR data. K. Gierens and B. Mayer (both DLR) we thank for their constructive and helpful comments, B. Mayer also for the cloud photo in Fig. 1.

Edited by: P. Spichtinger

\section{References}

Anderson, G. P., Clough, S. A., Kneizys, F. X., Chetwynd, J. H., and Shettle, E. P.: AFGL Atmospheric Constituent Profiles (0120 km), AFGL-TR-86-0110, AFGL (OPI), Hanscom AFB, MA 01736, 1986

Bennartz, R.: Global assessment of marine boundary layer cloud droplet number concentration from satellite, J. Geoph. Res., 112, D02201, doi:10.1029/2006JD007547, 2007.

Brenguier, J.-L., Pawlowska, H., Schüller, L., Preusker, R., Fischer, J., and Fouquart, Y.: Radiative properties of boundary layer clouds: droplet effective radius versus number concentration, J. Atmos. Sci., 57, 803-821, 2000.

Chakrapani, V., Doelling, D. R., Rapp, A. D., and Minnis, P.: Cloud Thickness Estimation from GOES-8 Satellite Data Over the ARM-SGP Site, Twelfth ARM Science Meeting Proceedings, St. Petersburg, Florida, April 8-12, 2002.

EUMETSAT: MSG-1/SEVIRI Solar Channels Calibration Commissioning Activity Report, EUM/MSG/TEN/04/0024, 2004.

Forsythe, J. M., Vonder Haar, T. H., and Reinke, D. L.: CloudBase Height Estimates Using a Combination of Meterological 
Satellite Imagery and Surface Reports, J. Appl. Meteorol., 39, 2336-2347, 2000.

Hutchison, K. D.: The retrieval of cloud base heights from MODIS and three-dimensional cloud fields from NASA's EOS Aqua mission, Int. J. Remote Sens., 23(24), 5249-5265, 2002.

Krebs, W., Mannstein, H., Bugliaro, L., and Mayer, B.: Technical note: A new day- and night-time Meteosat Second Generation Cirrus Detection Algorithm MeCiDA, Atmos. Chem. Phys., 7, 6145-6159, 2007, http://www.atmos-chemphys.net/7/6145/2007/.

Kriebel, K. T., Gesell, G., Kästner, M., and Mannstein, H.: The cloud analysis tool APOLLO: improvements and validations, Int. J. Remote Sens., 24(12), 2389-2408, 2003.

Kassianov, E., Ackermann, T., Marchand, R., and Ovtchinnikov, M.: Satellite multiangle cumulus geometry retrieval: Case study, J. Geophys. Res., 108(D3), 4117, doi:10.1029/2002JD002350, 2003.

Lawrence, M. G.: The Relationship between Relative Humuditiy and the Dewpoint Temperature in Moist Air, A simple Conversion and Applications, B. Am. Meteorol. Soc., 86, 225-233, doi:10.1175/BAMS-86-2-225, 2005.

Mayer, B. and Kylling, A.: Technical note: The libRadtran software package for radiative transfer calculations - description and examples of use, Atmos. Chem. Phys., 5, 1855-1877, 2005, http://www.atmos-chem-phys.net/5/1855/2005/.

Meerkötter, R. and Zinner, T.: Satellite remote sensing of cloud base height for convective cloud fields: A case study, Geophys. Res. Lett., 34, L17805, doi:10.1029/2007/GL030347, 2007.
Minnis, P., Kratz, D. P., Coakley Jr., J. A., King, M. D., Garber, D., Heck, P., Mayor, S., Young, D. F., and Arduini, R.: Cloud Optical Property Retrieval (Subsystem 4.3), in: Clouds and the Earth's Radiant Energy System (CERES) Algorithm Theoretical Basis Document, Volume III: Cloud Analyses and Radiance Inversions (Subsystem 4), NASA RP 1376 Vol. 3, edited by: CERES Science Team, December, 135-176, 1995.

Nakajima,T. and King, M. D.: Determination of the optical thickness and effective particle radius of clouds from reflected solar radiation measurements, Part I: Theory, J. Atmos. Sci., 47, 18781893, 1990.

Schmetz, J., Pili, P., Tjemkes, S., Just, D., Kerkmann, J., Rota, S., and Ratier, A.: Supplement to An Introduction to Meteosat Second Generation (MSG), B. Am. Meteorol. Soc., 83, 977-992, 2002.

Weisz, E., Li, J., Menzel, W. P., Heidinger, A. K., Kahn, B. H., and Liu, C.-Y.: Comparison of AIRS, MODIS, CloudSat and CALIPSO cloud top height retrievals, Geophys. Res. Lett., 34, L17811, doi:10.1029/2007GL030676, 2007.

Wilheit Jr., T. T. and Hutchison, D.: Retrieval of Cloud Base Heights from Passive Microwave and Cloud Top Temperature data, IEEE T. Geosci. Remote Sens., 38(3), 1253-1259, 2000.

Zinner, T., Mayer, B., and Schröder, M.: Determination of threedimensional cloud structures from high-resolution radiance data, J. Geophys. Res., 111, D08204, doi:10.1029/2005JD006062, 2006. 